\title{
Substrate bias voltage and deposition temperature dependence on properties of rf-magnetron sputtered titanium films on silicon (100)
}

\author{
B GEETHA PRIYADARSHINI ${ }^{1, *}$, SHAMPA AICH ${ }^{2}$ and MADHUSUDAN CHAKRABORTY ${ }^{2}$ \\ ${ }^{1}$ Materials Science Division, PSG Institute of Advanced Studies, Peelamedu, Coimbatore 641 004, India \\ ${ }^{2}$ Department of Metallurgical and Materials Engineering, Indian Institute of Technology, Kharagpur 721 302, India
}

MS received 10 November 2012

\begin{abstract}
Thin films or a coating of any sort prior to its application into real world has to be studied for the dependence of process variables on their structural and functional properties. One such study based on the influence of substrate conditions viz. substrate-bias voltage and substrate temperature on the structural and morphological properties, could be of great interest as far as Ti thin films are concerned. From X-ray texture pole figure and electron microscopy analysis, it was found that substrate bias voltage strongly influence preferential orientation and morphology of Ti films grown on $\mathrm{Si}(100)$ substrate. Deposition at higher substrate temperature causes the film to react with $\mathrm{Si}$ forming silicides at the film/Si substrate interface. Ti film undergoes a microstructural transition from hexagonal plate-like to round-shaped grains as the substrate temperature was raised from 300 to $50{ }^{\circ} \mathrm{C} \mathrm{during} \mathrm{film}$ deposition.
\end{abstract}

Keywords. Magnetron; thin films; texture; morphology; microscopy; X-ray diffraction.

\section{Introduction}

Titanium based coatings owing to their remarkable properties like wear and corrosion resistance, thermal and chemical stability, high specific strength have gained much attention as diffusion barrier layers, interlayers in semiconductor device and orthodontic applications (Boyer 1996; Martin et al 1998; Jeyachandran et al 2006; Song et al 2007). Ti interlayer of $\sim 4 \mathrm{~nm}$ thickness introduced between gold thin film and quartz is reported to improve the adhesion properties of gold electrode to the substrate (Hoogvliet and Bennekom 2001; Aouani et al 2009). Particularly, ultra thin Ti is known to act as protective sacrificial layer between metallic silver $(\mathrm{Ag})$ and dielectric layers $\left(\mathrm{SnO}_{2}\right)$ by preventing the latter from oxidizing with dielectric layer (Godfroid et al 2003). Recently, thin layer of $\mathrm{Ti}$ is considered to be a good candidate for nuclear micro batteries due to higher tritium storage capacity (Lee et al 2009). Over the years, there was an immense focus into the development of ohmic contacts, schottky barriers and local interconnectors for verylarge-scale integrated systems (VLSI) due to low resistivity, thermal stability and chemical compatibility of titanium silicides (Wan and Wu 1997; Sakta et al 2006). Si is known to be the primary diffusion species in $\mathrm{Ti} / \mathrm{Si}$ system, therefore, at temperatures below $700^{\circ} \mathrm{C} \mathrm{TiSi}$ and $\mathrm{TiSi}_{2}$ are formed. Formation of titanium silicides follows a series of intermediate steps leading to the formation of metastable C49 phase of

*Author for correspondence (geethapriyadarshini@gmail.com)
$\mathrm{TiSi}_{2}$ at a temperature of $450-550{ }^{\circ} \mathrm{C}$, whereas a stable C54 phase of $\mathrm{TiSi}_{2}$ above $650-700^{\circ} \mathrm{C}$ (Pérez-rigueiro et al 1997). Therefore, Ti layer purity and its thickness on Si substrates decide the final thickness of titanium silicides and its sheet resistance (Sakta et al 2006).

Based on extensive literature review, various research groups had employed electron beam heating (Bunshah and Juntz 1973), conventional direct current (dc) magnetron sputtering (Jung et al 2003; Savaloni et al 2004; Jeyachandran et al 2007; Chawla et al 2008; Zhang et al 2009; Jin et al 2009; Chang et al 2010), pulsed d.c. and radio frequency (rf) magnetron sputtering (Oya and Kusano 2009), facing target sputtering (FTS) (Naoe et al 1991), filtered arc evaporation (Bendavid et al 1996), ion-beam sputtering (Yu and Wang 1997), triode magnetron sputtering (Fontana and Muzart 1998) and pulsed magnetron sputtering (Henderson et al 2003) for deposition of Ti thin films. It is well acknowledged that the structural and physical properties of deposited thin films are greatly influenced by the processing condition irrespective of the deposition technique employed (Ohring 2006).

Song et al (2007) observed that the substrate and substrate to target distance had influenced the preferential orientation and roughness of Ti grains grown by rf sputtering. Recently, Dasgupta et al (2011) studied growth of Ti films on $\mathrm{Cu}$, glass and $\mathrm{Si}$ substrates. Polycrystalline films with fine $\mathrm{Ti}$ grain size were found to grow on $\mathrm{Cu}$ substrates. While textured $\mathrm{Ti}$ films with coarse grains was observed when deposited on $\mathrm{Si}$ and glass. Yet another important parameter, deposition power influences the grain size, morphology, crystallinity and preferential orientation of $\mathrm{Ti}$ grains as a result of increase in 
deposition rate and atomic mobility on the growing surface (Jeyachandran et al 2007; Chawla et al 2008; Jin et al 2009).

Savaloni et al (2004) observed change in the nature of stress from tensile to compressive for lower Ti film thickness. Beyond a critical thickness of $\sim 330 \mathrm{~nm}$, stress reversal from compressive to tensile stress is observed with increase in film thickness. Further, Jeyachandran et al (2007) observed increase in Ti film thickness on the sheet resistance, which was found to decrease from 14.3 to $3.6 \Omega / \mathrm{m}$ and increase in temperature co-efficient of resistance value from $0 \cdot 14$ to $0.20 \% \mathrm{~K}^{-1}$, possibly due to the development of stress which was found to shift the preferential orientation from (002) to (100).

Deposition pressure is one of the crucial process parameters which decides the microstructural properties of growing thin film thereby affecting device properties. In case of Ti thin films deposited by FTS method (Bendavid et al 1996), reduction of Ar gas pressure deteriorated the crystallinity and (002) preferred orientation, instead it produced a smooth surface and dense morphology. Whereas, increase in Ar gas pressure Ti film showed improvement in (002) orientation along with coarse grain morphology. To have advantages of above two cases, Ti films were deposited initially at high pressure and later the pressure was lowered leading to epitaxial Ti layer having (002) orientation and smooth dense morphology. Chawla et al (2008) investigated Ti films under the action of increased Ar gas pressure which lead to change of preferential orientation from (002) to (101) in conjunction with increase in grain size and surface roughness. This was due to a large number of collisions between target atoms and $\mathrm{Ar}$ ions, which resulted in higher probability of agglomeration before arriving at the substrate. Jeyachandran et al (2006) observed an increase in background pressure leading to the development of amorphous Ti films with incorporation of residual impurities leading to complete oxidation at surface of Ti films. Further same group investigated the effect of increase in Ar gas pressure during deposition resulting into complete oxidation at the bulk of Ti film, which resulted in degradation in (002) film crystallinity. Recently, Oya and Kusano (2009) deeply investigated the effect of deposition pressure on the structure and properties of Ti films deposited using different sputtering sources. They found that irrespective of deposition method employed for growing $\mathrm{Ti}$ films, higher Ar gas pressure are found to increase roughness of the films thereby reducing the reflectance and thereby increasing Ti film resistivity. In addition, internal stresses in Ti films were found to change from compressive to tensile mode with increase in the deposition pressure along with morphological evolution from smooth to rough surface.

According to Thornton's structural zone model (SZM) for sputtered thin films, Ar gas pressure and $T_{\mathrm{s}} / T_{\mathrm{m}}$ (ratio of substrate temperature to melting temperature of target species) are two prime parameters which determine the microstructure of deposited thin films dictated by adatom mobility (Thornton 1974, 1986). Thin metallic films deposited substrate held at room temperature usually shows zone I type of microstructure with fine-columnar grain morphology due to insufficient adatom mobility. The rate at which the surface diffusion of adatoms takes place on the substrate controls the microstructure of the resulting films, which are subjective to substrate temperature and substrate bias voltage applied during deposition. Change in preferential orientation of Ti grains, improvement in crystallinity, grain growth with smooth and dense columnar microstructure, morphological evolution in Ti grains takes place when Ti films are deposited at elevated substrate temperature (Naoe et al 1991; Chawla et al 2008, 2009). Residual stress was also found to change from compressive to tensile with increase in $T_{\mathrm{s}} / T_{\mathrm{m}}$ for Ti films (Savaloni et al 2004). Yet another report by Chang et al (2010) states that the residual stress decreases as the substrate temperature increases, in which the stress changes from tensile to compressive when the substrate temperature increases.

Introduction of substrate bias voltage in FTS of Ti films showed degradation in crystallinity by encouraging preferential growth of (010) and (011) instead of (002) Ti grains and further increase of bias voltage lead to re-sputtering of $\mathrm{Ti}$ adatoms from growing film due to enhanced Ar ion bombardment (Chang et al 2010). Ljungcrantz et al (1993) reported stress variation from tensile to compressive upon increasing the bias voltage from 0 to $-300 \mathrm{~V}$ in Ti films. Increase of substrate bias voltage from 0 to $-150 \mathrm{~V}$ shows the change in preferential orientation of Ti grains from (002) to (100) and lead to densification (Jung et al 2003). A great deal of work on Ti films is limited to d.c. magnetron sputtering technique. However, earlier report by Martin et al (1998) described the effect of r.f bias power on the growth morphology of Ti films prepared by rf magnetron sputtering and observed the cleaning action, knocking, and re-sputtering leading to densification as well as decrease in deposition rate.

Sputtering process involves the formation of crystals from vapour state due to high cooling rate of $10^{12} \mathrm{k} / \mathrm{s}$. This enormous quench rate is known to produce amorphous thin films in which the mobility of metal atoms is suppressed by rapidly freezing of adatoms on the substrate surface. However, the fact is that it is practically not possible to restrict the adatom mobility even at room temperature due to random vibrational frequency $(v)$. The jump or hopping rate $(\Gamma)$ defined by

$$
\Gamma=v \exp \left[\frac{-E_{\mathrm{diff}}}{k_{\mathrm{B}} T}\right]
$$

where $E_{\text {diff }}$ is the potential energy barrier to diffusion, $k_{\mathrm{B}}$ Boltzmann constant and $T$ the temperature. The above equation decides the morphological and structural properties of growth layer by aiding surface diffusivity of adatoms. Therefore, our interest is based on simple fact that the substrate temperature and ion-bombardment reduce the potential energy barrier to diffusion thereby aiding surface diffusion of Ti adatoms. Henceforth, the present work is intended to carry out based on the fact that the substrate temperature and ion-bombardment during deposition has a role to play in aiding surface diffusion and modifying the properties of $\mathrm{rf}$ magnetron sputtered Ti thin films on Si substrates. 


\section{Experimental}

\subsection{Deposition of Ti films}

Titanium films were deposited using a RF magnetron sputtering system (KVT Ltd., Korea) with three gun 'sputterdown setup' details of which described elsewhere (Geetha Priyadarshini et al 2011). The sputter chamber was evacuated to a base pressure lower than $3 \times 10^{-6}$ Torr using turbo-molecular pump driven by rotary pump and was measured by ion-gauge. $99.9 \%$ pure Ti with a diameter of $3^{\prime \prime}$ was employed as the sputter target and rf matching was controlled to fix the power. Argon gas of $99.99 \%$ purity was used as sputtering gas with constant flow rate of $50 \mathrm{sccm}$. Argon gas pressure was controlled by the throttle valve and was measured using MKS Baraton pressure gauge. Titanium films were deposited onto $3 \times 3 \mathrm{~cm}$ p-type Si (100) substrates, which were ultrasonically cleaned with acetone and alcohol. Prior to deposition, substrates were etched with $2 \% \mathrm{HF}$ solution in order to remove native oxide layer on the surface. To ensure purity of deposited films, pre-sputtering of titanium target for about 5 min was done to remove surface oxides. In order to maintain uniformity in film thickness, the substrates were rotated at $10 \mathrm{rpm}$ for all the depositions. The details of deposition parameters employed are tabulated in table 1 .

\subsection{Characterization of Ti films}

2.2a Field-emission scanning electron microscopy: Studies on microstructure and nature of film growth were done on both planar and cross-sectional titanium films by Carl ZeissSUPRA40 field-emission gun scanning electron microscope with an acceleratized voltage of $5 \mathrm{kV}$ and a magnification upto $200 \mathrm{kX}$.

2.2b X-ray diffraction and thin film texture analysis: X-ray diffraction (XRD) studies were performed on a PANalytical High Resolution PW 3040/60 diffractrometer, with CuK $\alpha$ radiation. Conventional $\theta-2 \theta$ and grazing incidence geometries were employed to study crystallinity of the films. In conventional geometry, the scan range was kept at $2 \theta=31-41^{\circ}$ with a scan step size of 0.016. In grazing incidence geometry, the tube was set to an accelerating voltage of $40 \mathrm{kV}$ at a current of $30 \mathrm{~mA}$ and the grazing angle $(\alpha)$ was fixed at $0.5^{\circ}$ with a scan step size of $0.05^{\circ}$ over an angle range of $2 \theta=30$ $-50^{\circ}$. Thin film phase analysis by GIXRD was carried out in asymmetric configuration by using beam-selective technique of parallel beam optics. A combination of very small divergence slit together with a parallel plate collimator is used in the quasi-parallel beam geometry. A programmable divergence slit module and anti-scatter slit was employed to fix the adjustable divergence slit to an angle $1 / 4^{\circ}$. This controls the divergence in equatorial plane. Soller slit of opening dimension of $0 \cdot 04$ radians was used to control the divergence in axial plane. For line focusing, incident beam mask was employed with a size $10 \mathrm{~mm}$ of the opening to completely accept the incident X-ray beam by the sample. In the secondary side, diffracted beam is collimated through parallel plate collimator (PPC) which comprises of set of parallel plates, which are perpendicular to diffraction planes. The distance between the plates inside the collimator and the angle between the diffracted beam and the sample surface define length of the sample. This is used in combination with an incident beam optical module providing X-ray beam with very low divergence by divergence slit. PPC defines the equatorial acceptance of $0.18^{\circ}$ which is half-angle opening. In the diffracted path of the parallel beam geometry, Soller slit is used to control the axial acceptance. PreFix PPC module was interfaced to the proportional detector which is mounted on PPC.

Thin film texture measurements were carried out in a PAN-alytical X'pert MRD diffractometer equipped with parallel beam optics and an Eulerian cradle. The system allows the cradle to rotate around the axis normal to the sample $(\phi)$ and to tilt the sample parallel to the substrate $(\psi)$. Pole figure measurements were recorded for (100) and (101) reflections of Ti thin films using $\mathrm{CuK} \alpha$.

Table 1. Deposition details of titanium thin films.

\begin{tabular}{lcccccc}
\hline $\begin{array}{l}\text { Ar gas } \\
\text { pressure } \\
(\text { mtorr })\end{array}$ & $\begin{array}{c}W D_{\mathrm{TS}} \\
(\mathrm{mm})\end{array}$ & Power $(\mathrm{W})$ & $\begin{array}{c}\text { Substrate- } \\
\text { bias } \\
\text { voltage }(\mathrm{V})\end{array}$ & $\begin{array}{c}\text { Substrate } \\
\text { temperature } \\
\left({ }^{\circ} \mathrm{C}\right)\end{array}$ & $\begin{array}{c}\text { Deposition } \\
\text { time }(\mathrm{min})\end{array}$ & $\begin{array}{c}\text { Thickness } \\
(\mathrm{nm})\end{array}$ \\
\hline & & & & & \\
10 & 150 & 300 & -10 & 30 & 10 & $90 \pm 0 \cdot 5$ \\
10 & 150 & 300 & -30 & 30 & 10 & $80 \pm 0 \cdot 1$ \\
10 & 150 & 300 & -50 & 30 & 10 & $80 \pm 0 \cdot 1$ \\
10 & 150 & 300 & -70 & 30 & 10 & $70 \pm 0 \cdot 5$ \\
10 & 150 & 300 & -90 & 30 & 10 & $60 \pm 0 \cdot 5$ \\
& & & Set 1 & & 30 & $250 \pm 1$ \\
20 & 150 & 300 & Unbiased & 30 & 30 & $250 \pm 1$ \\
20 & 150 & 300 & Unbiased & 300 & 30 & $250 \pm 1$ \\
20 & 150 & 300 & Unbiased & 500 & & \\
\hline
\end{tabular}




\section{Results and discussion}

\subsection{Film morphology}

When negative bias voltage is applied to substrate, low energy Ar ions from the plasma are attracted near to the substrate end acting as a secondary target. Table 1 shows that the film thickness decreases steeply with increase in bias voltage from 0 to $-30 \mathrm{~V}$ and thereafter, there is a gradual decrease in film thickness, which is expected to affect various properties. Onset of deposition in the presence of negative substrate bias causes Ar ions to be attracted towards the substrate and these ions scatters-off Ti adatoms subsequently leading to the lowering of deposition rates as observed in figure 1 .

The rate at which ions are bombarded increases with increasing substrate-bias voltage and this was found to affect the physical structure of films similar to that of increasing the gas pressure during deposition. Upon introducing ion-bombardment, the jump diffusion rate $(\Gamma)$ is modified as:

$$
\Gamma=v \exp \left[\frac{-\left(E_{\mathrm{diff}}-E_{\mathrm{i}}\right)}{k_{\mathrm{B}} T}\right],
$$

where $E_{\text {diff }}$ is the activation energy for diffusion due to transfer of the energy $\left(E_{\mathrm{i}}\right)$ and momentum to the surface atoms by ion (Makeev and Barabasi 1997). Planar FE-SEM images and corresponding cross-sectional FE-SEM images as inset at varying substrate bias voltage $(-10,-50$ and $-90 \mathrm{~V})$ during Ti depositions are shown in figure $2(\mathrm{a}-\mathrm{c})$. From crosssectional FE-SEM images (inset of figure 2(a-c)), film thickness was observed to reduce from $\sim 100$ to $\sim 60 \mathrm{~nm}$ with increase in bias voltage from -10 to $-90 \mathrm{~V}$ and agrees well with the data obtained from surface profiler (table 1). At $-10 \mathrm{~V}$, Ti films exhibit disintegrated columnar structure accompanied with porous structure. As the bias voltage was

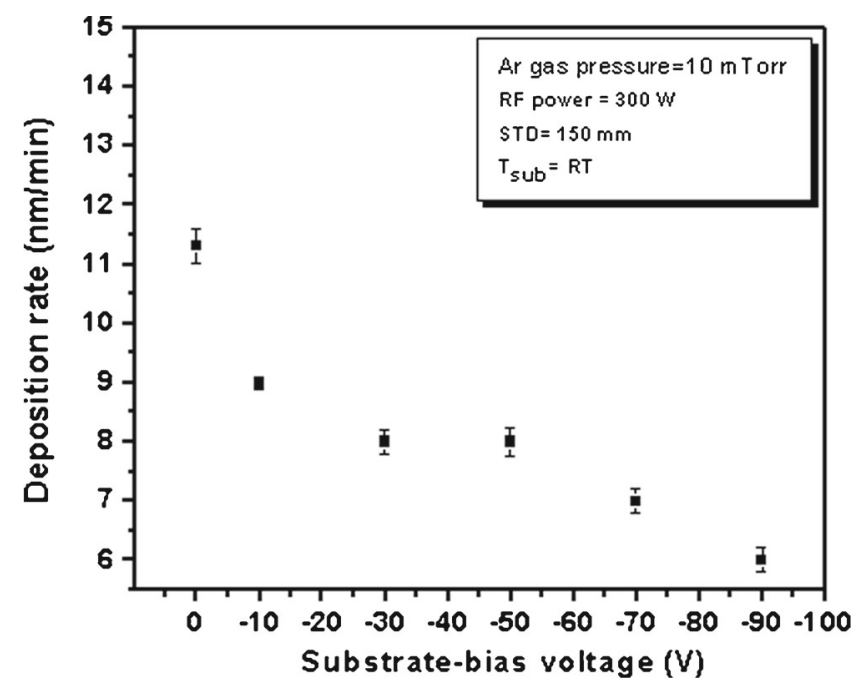

Figure 1. Deposition rates of Ti films at different substrate-bias voltages. increased to $-50 \mathrm{~V}$, the columnar structure changed to dense smooth-continuous structure which is the consequence of increased surface diffusivity of Ti adatoms to occupy nearby low potential sites. However, with increase in the bias voltage upto $-90 \mathrm{~V}$, Ti grains were found to reduce in size suggesting that higher ion bombardment not only delivers sufficient energy to adatom for surface diffusion but also shows tendency towards re-sputtering from growing film surface leading to smoothening of surface features. Disruption of densecontinuous structure due to enhanced re-sputtering from $\mathrm{Ti}$ film surface was observed at a high bias voltage of $-90 \mathrm{~V}$ (figure 2c). Re-sputtering process tends to increase defect sites, i.e. heterogeneous nucleation sites during deposition. Therefore, numerous grains nucleate simultaneously on the substrate and hence, face difficulty to grow in size as their mobility is restricted by encountering with new neighbouring grains. This increase of nucleation sites accompanied with hindrance caused during film growth facilitates the formation of fine-grained Ti films.
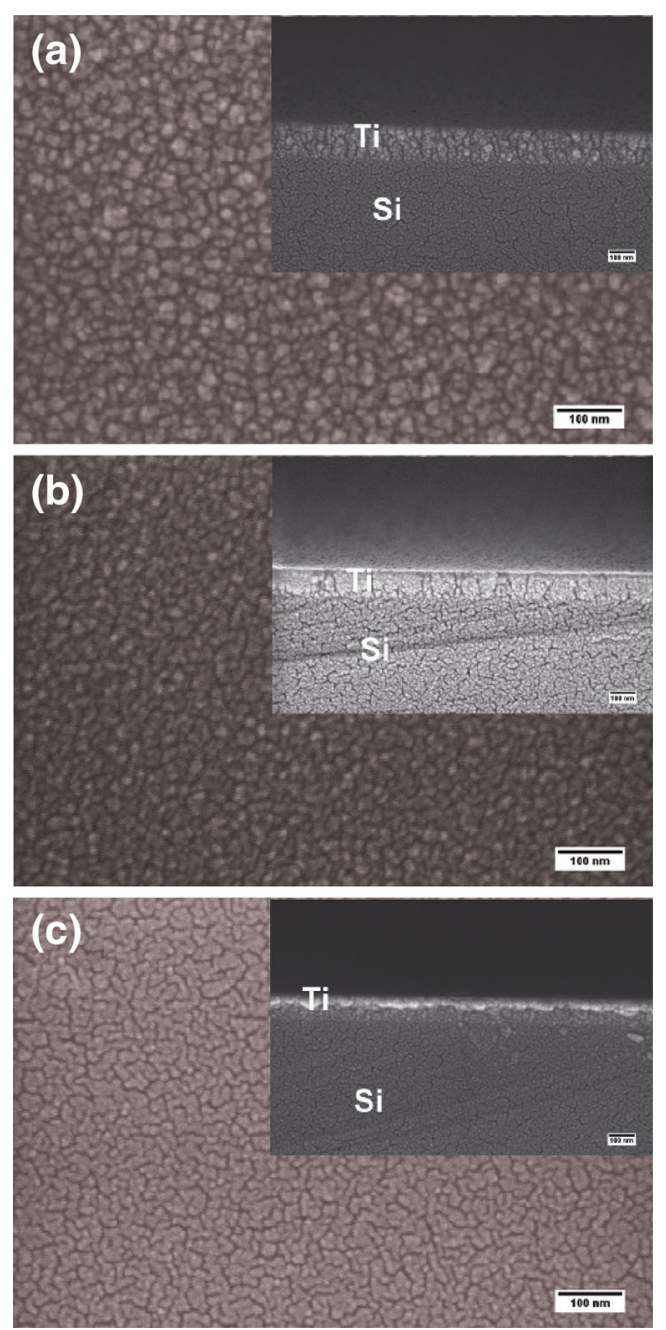

Figure 2. Planar and cross-sectional FESEM images of Ti films deposited at (a) $-10 \mathrm{~V},(\mathbf{b})-50 \mathrm{~V}$ and (c) $-90 \mathrm{~V}$ substrate-bias voltages (inset shows corresponding cross-sectional images). 
Figure 3(a-c) reveals planar and cross-sectional FE-SEM images of $\mathrm{Ti}$ films at varying substrate temperature (30, 300 and $500^{\circ} \mathrm{C}$ ). It is clearly observed that the increase in deposition temperature leads to the growth of $\mathrm{Ti}$ grains with increase in grain size due to higher driving force associated with grain boundary free energy at higher substrate temperature. Further, Ti films deposited at $300^{\circ} \mathrm{C}$ exhibit 2d-hexagonal plate-like structures. Upon increasing the substrate temperature to $500^{\circ} \mathrm{C}$, Ti films comprise of 3d-spherical-like grain morphology with uniform grain size distribution. At high deposition temperature, additional bulk diffusion with grain boundary migration might lead to increase in size and change in shape of grains. Similar type of morphological change at different substrate temperatures for d.c. sputtered Ti films was observed by Chawla et al (2008, 2009). Change in the morphology of grains from $2 \mathrm{~d}$-hexagonal to $3 \mathrm{~d}$-spherical type could be possible due to change in the preferential orientation, which would be explored in detail in forthcoming sections. The
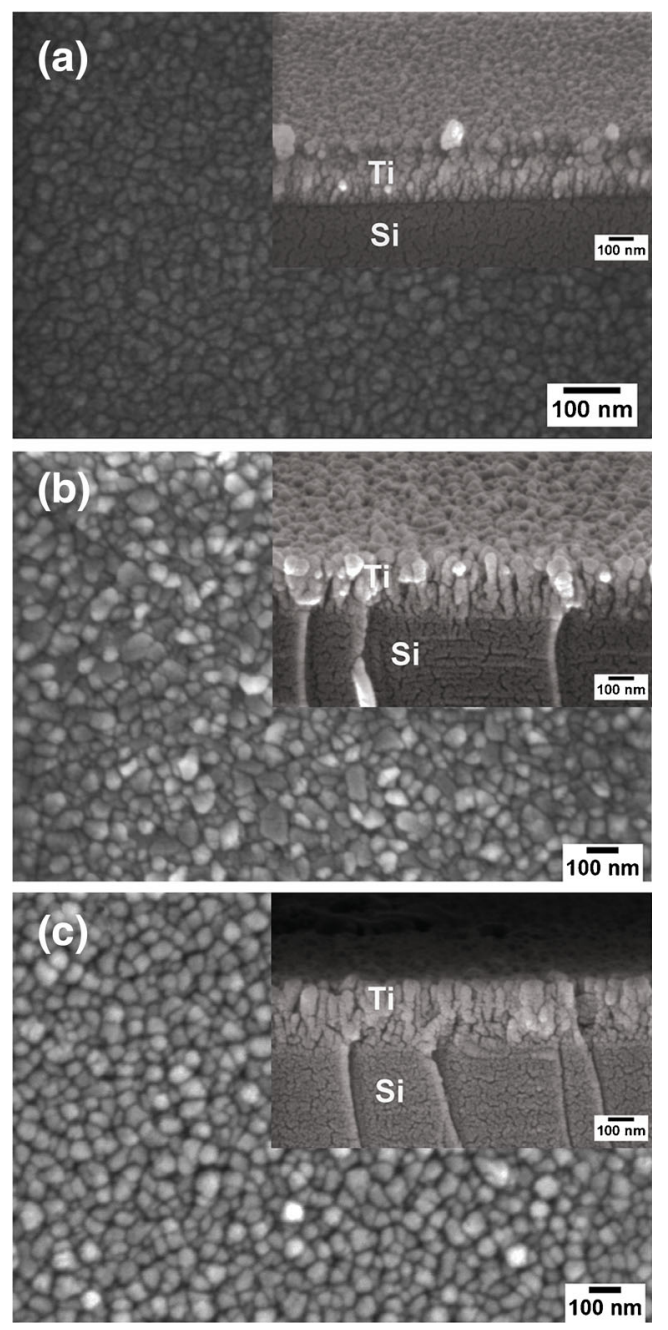

Figure 3. Planar and cross-sectional FESEM images of Ti films deposited at (a) $30{ }^{\circ} \mathrm{C}$, (b) $300^{\circ} \mathrm{C}$ and (c) $500^{\circ} \mathrm{C}$ substrate temperatures (inset shows corresponding cross-sectional images). cross-sectional micrographs show fibrous columnar which are not well-defined for films deposited at high temperature. According to SZM for sputtered films, microstructure of films are governed by the ratio of $T_{\mathrm{s}} / T_{\mathrm{m}}$ which enhances the surface diffusion of adatoms. In the present case, Ti films exhibit zone T-type $\left(T_{\mathrm{s}} / T_{\mathrm{m}}>0.3\right)$ of microstructure which tends to show fibrous columnar morphology.

\subsection{Film crystallinity and texture}

The prominent Bragg peaks in XRD patterns could be indexed to Ti hcp structure ( $a=0.2944 \mathrm{~nm}$ and $c=0.4679$ $\mathrm{nm})$. From XRD profiles, it is evident that Ti grains are predominantly oriented in $(10 * 0)$ plane centred at $2 \theta=34 \cdot 5^{\circ}$. Figure 4(a) shows GIXRD pattern for Ti films deposited at varying negative substrate bias voltage for constant Ar gas pressure of 10 mtorr and deposition time of $10 \mathrm{~min}$. Ti films tend to show degradation in film crystallinity irrespective of increase in the ion-bombardment energy. Ti films deposited at $-90 \mathrm{~V}$ bias voltage show degradation in the crystallinity due to enhanced re-sputtering of $\mathrm{Ti}$ adatoms from the growing film surface. The nucleation or defect sites might increase in number due to enhanced Ar-ion bombardment
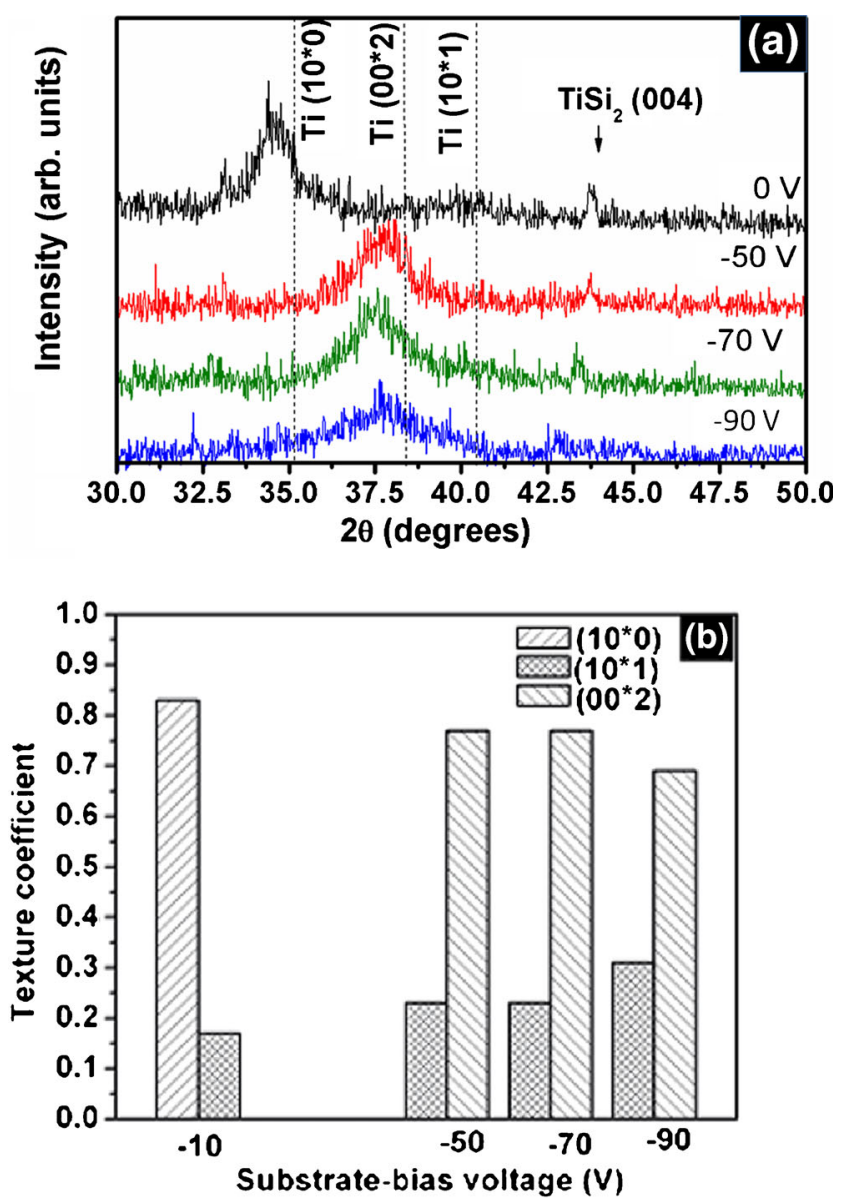

Figure 4. (a) GIXRD profiles and (b) texture coefficient plots for Ti films deposited at different substrate-target voltages. 
which causes nucleation of $\mathrm{Ti}$ grains. Therefore, with increase in number of such nucleation sites, Ti grains face difficulty to grow thus, leading to finer grain structure. In addition, the grain size could also be affected by the substrate-bias voltage, which strongly influence the preferential orientation of rf magnetron sputtered Ti films. The texture coefficients $(T)$ of Ti films deposited on Si substrates are calculated from GIXRD peaks using the following formula:

$$
T=\frac{I\left(h k^{*} l\right)}{I(10 * 0)+I(00 * 2)+I(10 * 1)},
$$

where $(h k l)$ are $(10 * 0),(00 * 2)$ or $(10 * 1)$ orientations and $I$ the relative intensity (Chawla et al 2009). The texture coefficient is slightly affected by argon gas pressure as shown in figure 4(b). From the texture coefficient plot (figure 4b), it is clearly demonstrated that the substrate-bias voltage greatly influences orientation of the film.

In order to estimate the preferential orientation of $\mathrm{Ti}$ crystallites, films deposited at -10 and $-70 \mathrm{~V}$ were selected for XRD pole figure texture analysis, because there has been a complete change in preferential orientation as evident from XRD profiles. Figure 5(a and b) shows 3-D $\{10 * 0\}$ pole figure at $2 \theta=35^{\circ}$ for Ti films deposited at $-10 \mathrm{~V}$. A tilt angle of $\psi=0^{\circ}$ and rotation angle of $\phi=0^{\circ}$ shows maximum intensity suggesting that Ti surface normal of $(10 * 0)$ crystallites are nearly parallel to the film surface. In addition, intensity vs tilt angle plot, shown in figure 5(c), suggests that $(10 * 0)$ intensity is maximum at a tilt angle of $\Psi=0^{\circ}$. However, $\{10 * 0\}$ pole figure for Ti films deposited at $-70 \mathrm{~V}$, shows maximum pole density at $\psi \sim 30^{\circ}$ suggesting that surface normal of $\{10 * 0\}$ is now oriented parallel to surface normal of $\{10 * 1\}$ orientation of Ti grains. However, the corresponding pole figure analysis does not show maximum intensity related to $(00 * 2)$ poles. In addition, intensity is found to be weakly dependent on $\psi$ suggesting that the crystallites are highly misoriented. $(10 * 0)$ intensity is the highest at tilt angle $\psi=25^{\circ}$, which complements the above findings from 3-D pole figures. (a)

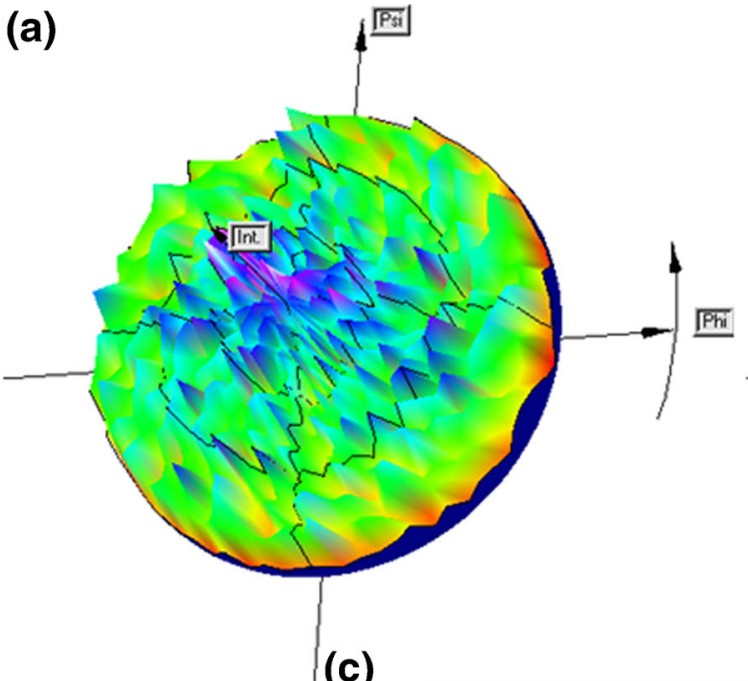

(c) (b)

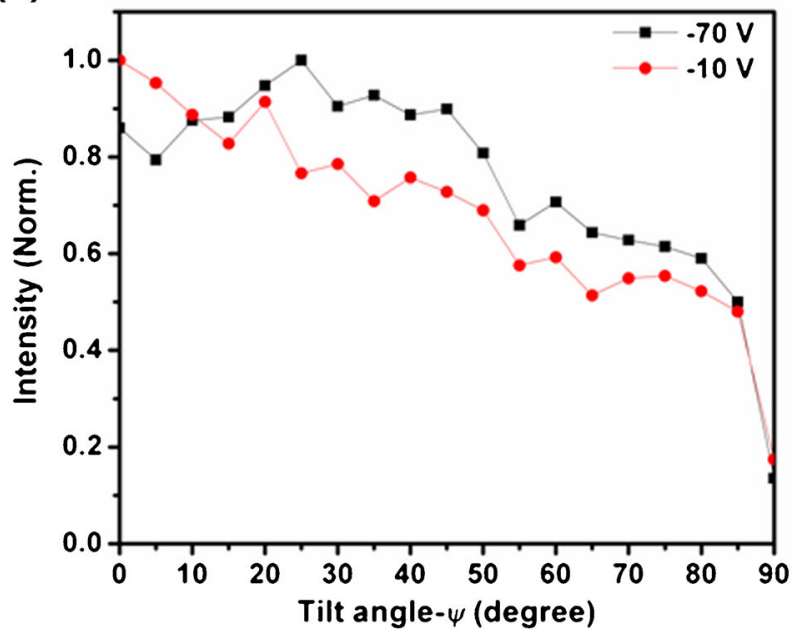

Figure 5. $\{10 * 0\}$ pole figure of Ti films deposited at (a) $-10 \mathrm{~V}$ (3-D representation), (b) $-70 \mathrm{~V}$ (3-D representation) and (c) tilt angle vs intensity plots at different substrate-bias voltages. 
In addition to change in the preferential orientation of $\mathrm{Ti}$ grains, it is observed that the peaks appearing in GIXRD profiles are slightly shifted to either higher or lower $2 \theta$ angle side suggesting shift in the lattice parameter. Lattice distortions viz. macro strain, micro strain and pseudo-macro strain are likely to be introduced due to the presence of internal stress present in a thin film which varies either with substrate material or with coating thickness (Rickerby et al 1989). Therefore, line shift due to the amount of macro strain present within the crystal lattice can be deduced from XRD patterns. The thermal expansion coefficient mismatch between film and substrate could lead to the origin of thermal strain in the film. Intrinsic strain $\left(\varepsilon_{i}\right)$ may develop due to the lattice mismatch between substrate and film, high deposition rates and presence of impurities. The intrinsic strain strongly depends on the deposition parameters and substrate material. Therefore, the total strain $\varepsilon$ (macro strain) in film is represented as shown in (4) (Guo and Alam 1992):

$$
\varepsilon=\varepsilon_{\mathrm{i}}+\left(\alpha_{\mathrm{f}}-\alpha_{\mathrm{s}}\right)(\Delta T),
$$

where $\alpha_{\mathrm{f}}$ and $\alpha_{\mathrm{s}}$ are thermal expansion coefficients of film and substrate, respectively. $\Delta T$ is the difference between deposition and room temperature. The macro strain can be calculated using (5) by obtaining $d$-spacing of the strained film (d) from GIXRD pattern (Guo and Alam 1992):

$$
\varepsilon=\frac{d_{0}-d}{d_{0}} .
$$

If $d$-spacing values are shifted from their normal position to either higher or lower value, presence of compressive or tensile strain in the film is seen. Therefore, the total strain present in Ti film deposited at different substrate-bias voltages are measured from the shifts in $(00 * 2)$ peak positions from GIXRD profiles by employing (3) and the corresponding values are tabulated below (table 2$)$. The change in preferential orientation from $(10 * 0)$ to $(00 * 2)$ at higher applied negative bias is considered to be developed in order to reduce the increased strain energy resulting from the more energetic impinging ions or could be due to decrease in film thickness. Surface and bulk diffusion are two atomic processes which control the structure evolution during film deposition. Apart from temperature, energetic particle bombardment could be other possible reason to affect the atomic processes.
Orientation selection during coalescence stage is more pronounced and is driven by a decrease in the total grain boundary area as well as minimization of interface and surface energy. Large grains with low surface and interface energy grow at the expense of smaller or unfavourably oriented grains.

Texture in thin films is controlled by both nucleation and growth. Lowering of interfacial energy (between Si and metal) as well as grain boundary energies (metal-metal) can be considered as the thermodynamic driving force. During deposition process, interfacial energy will be lower for certain orientation(s) compared to other(s) and initial texture is driven by nucleation. However, as the deposition continues the growth will occur in such a way that interfacial and grain boundary energies are reduced. Grains with low free surface and interface energy density grow faster than grains in the other orientation and can occupy a large volume fraction of the film. The strain energy can also influence orientation evolution at film formation stage. However, in thin film which has high surface to volume ratios, often this term is neglected taking surface as major contributor to the orientation change. Due to the same reasons, $f c c$ Ni films readily show dominant (111) orientation in as-deposited state due to low surface energy of $(111)\left(\gamma_{111}<\gamma_{110}<\gamma_{100}\right)$ when compared to other orientation during deposition (Thornton 1974). However, the kinetics is to be dictated by adatom mobility. The preference for (111) texture is also possible when appreciable mobility of adatoms is available, which occurs when bias voltage is higher or temperature is increased. Pelleg et al (1991) suggested that the preferred orientation of TiN thin films was caused by the driving force to reduce the overall energy of the film which is composed of surface and strain energies. They predicted that the film would grow towards the orientation of (200) plane with the lowest surface energy when surface energy is dominant, and towards orientation of the (111) plane with lowest strain energy when strain energy is dominant.

In $h c p$ Ti systems, $(00 * 2)$ are the densest planes which have the lowest surface free energy. But in the present case, it is observed that the films show change in texture orientation with change in substrate bias voltage as film thickness is reduced. The driving force for change in orientation is the competition between the surface free energy and interfacial free energy.

\begin{tabular}{|c|c|c|c|c|c|c|}
\hline Substrate conditions & $\begin{array}{c}\text { Peak } \\
\text { position }(2 \theta)\end{array}$ & $\begin{array}{l}(h k l) \\
\text { plane }\end{array}$ & $\begin{array}{c}\text { Observed } \\
d \text {-spacing }(\AA)\end{array}$ & $\begin{array}{c}\text { Standard } \\
d_{0} \text {-spacing }(\AA)\end{array}$ & $\begin{array}{c}\varepsilon \text { (macro } \\
\text { strain) }\end{array}$ & $\begin{array}{c}\varepsilon_{\mathrm{i}} \text { (Intrinsic } \\
\text { strain) }\end{array}$ \\
\hline \multicolumn{7}{|c|}{ Substrate-bias voltage (V) } \\
\hline-10 & $38 \cdot 39$ & $(00 * 2)$ & $2 \cdot 722$ & $2 \cdot 3395$ & $-0 \cdot 163$ & $-0 \cdot 163$ \\
\hline-50 & $37 \cdot 77$ & $(00 * 2)$ & $2 \cdot 765$ & $2 \cdot 3395$ & $-0 \cdot 181$ & $-0 \cdot 181$ \\
\hline-90 & 37.71 & $(00 * 2)$ & 2.769 & $2 \cdot 3395$ & $-0 \cdot 183$ & $-0 \cdot 183$ \\
\hline \multicolumn{7}{|c|}{ Substrate temperature $\left({ }^{\circ} \mathrm{C}\right)$} \\
\hline 300 & $40 \cdot 33$ & $(10 * 1)$ & $2 \cdot 236$ & $2 \cdot 240$ & 0.0017 & $1.87 \times 10^{-4}$ \\
\hline 500 & 39.79 & $(10 * 1)$ & $2 \cdot 265$ & $2 \cdot 240$ & $0 \cdot 0110$ & $-13.78 \times 10^{-3}$ \\
\hline
\end{tabular}

Table 2. Influence of substrate-bias voltage on lattice parameters and macro strain in Ti films. 
Further, it is attributed that compressive stresses induced by the damage created by on-bombardment might affect development of preferential orientation in Ti film

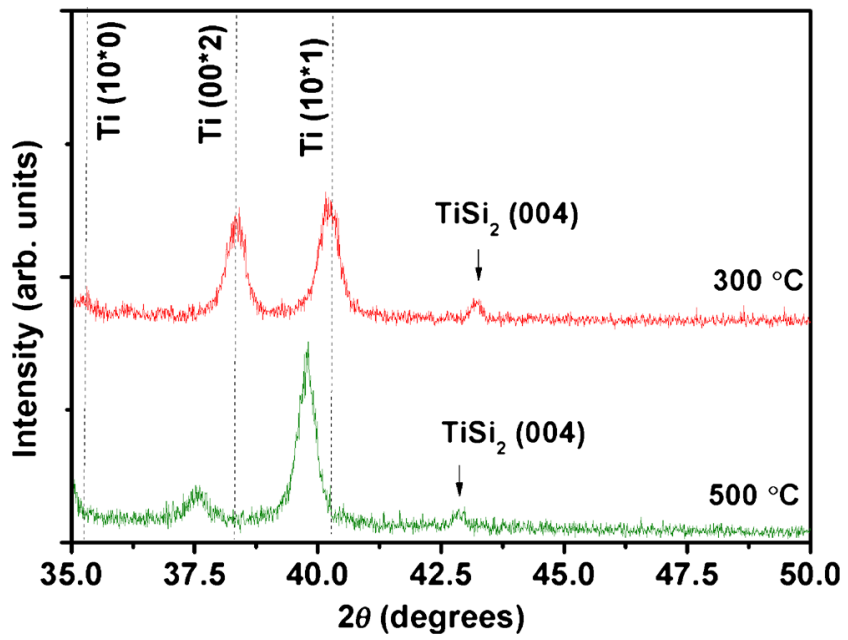

Figure 6. GIXRD profiles for Ti films deposited at different substrate temperatures.
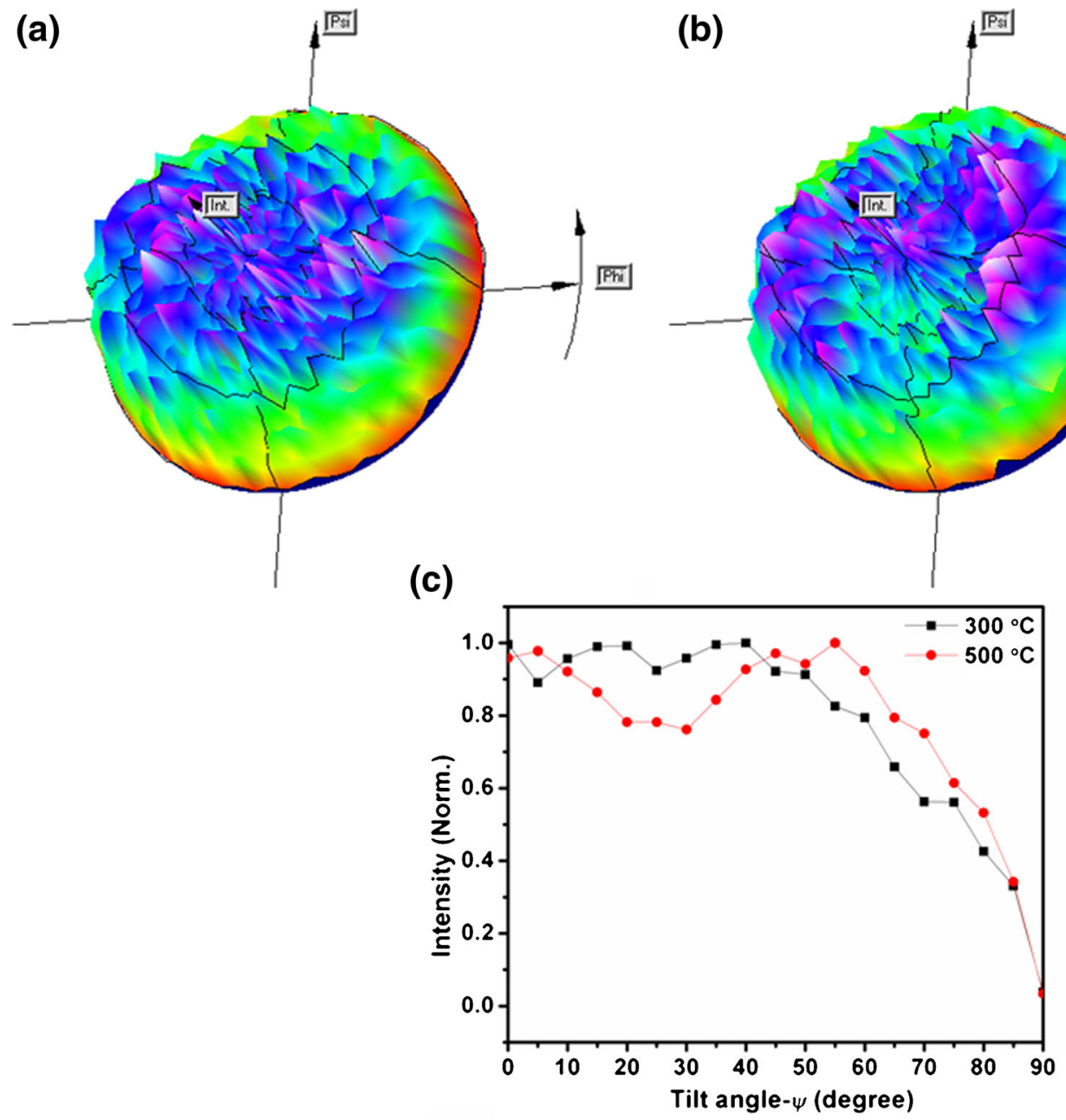

Figure 7. $\{10 * 1\}$ pole figure of Ti films deposited at (a) $300^{\circ} \mathrm{C}\left(3-\mathrm{D}\right.$ representation), (b) $500^{\circ} \mathrm{C}(3-\mathrm{D}$ representation) and (c) tilt angle vs intensity plots at different substrate temperatures.

(Bull et al 1992). The observed shift in the peak positions to lower angle side leads to the expansion of $d$-spacing of $(00 * 2)$ crystallite and is the consequence of atomic-peening effect due to energetic ion-bombardment. The expansion of the film surface takes place in order to accommodate defects produced during ion (neutrals) impact, which induces compressive stresses in the film. Bull et al (1992) also suggested 'ion-stuffing' as another possible reason for inducing compressive strain which lead to the expansion of surface regions by the inclusion of ions into the film thereby producing point defect and dislocation loops in the presence of high energetic ion-bombardment. Further, the shifting of $(00 * 2)$ peaks from their $2 \theta$ position also signifies that there is uniform strain present in the irradiated volume. It is observed that irrespective of different process parameters, compressive strains are induced in all Ti thin films.

Figure 6 shows GIXRD pattern for Ti films deposited at 300 and $500{ }^{\circ} \mathrm{C}$ substrate temperatures for constant rf power of $300 \mathrm{~W}$. Distinct crystalline peaks for Ti are found to be present due to high temperature depositions, which suggests growth of Ti grains. Three most intense peaks at $2 \theta=40 \cdot 2$, 38.35 and $35.23^{\circ}$ are indexed to $(10 * 1),(00 * 2)$ and $(10 * 0)$

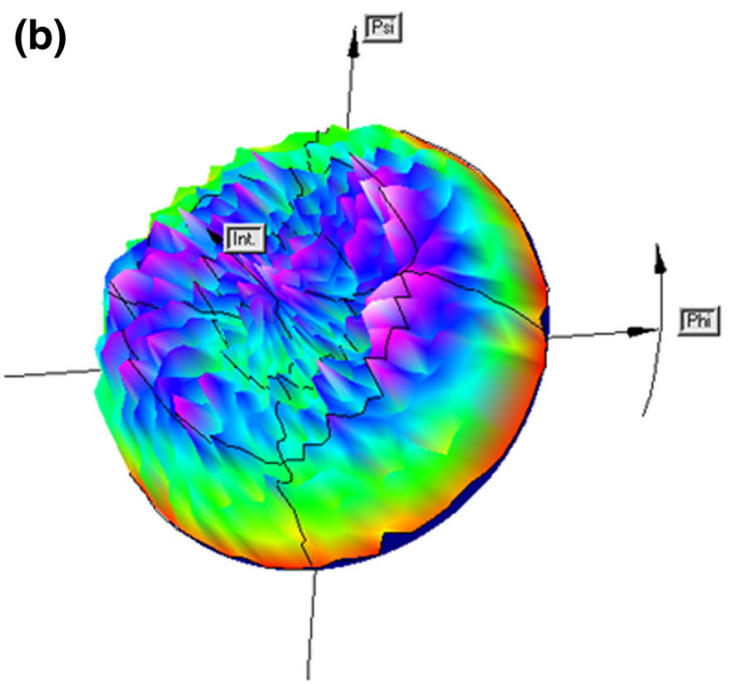


reflections for Ti films deposited at $300{ }^{\circ} \mathrm{C}$. A small peak at $2 \theta=43 \cdot 2^{\circ}$ is assigned to $\mathrm{Ti}_{5} \mathrm{Si}_{4}$ (302) peak, which suggests that $\mathrm{Ti}$ reacts with $\mathrm{Si}-\mathrm{O}$ layer at the interface during high temperature deposition. Ti film deposition at $500^{\circ} \mathrm{C}$ leads to the shifting of $(10 * 1)$ and $\mathrm{Ti}(10 * 0)$ peak to lower angle side and $\mathrm{Ti}(00 * 2)$ could not be indexed. This could be attributed to the nucleation of silicide phases at $2 \theta=42.86^{\circ}$ and $37.55^{\circ}$, which are indexed to $\mathrm{TiSi}_{2}(004)$ and $\mathrm{Ti}_{5} \mathrm{Si}_{3}$ (123) causing lattice strain in Ti film. Interestingly, increase in the deposition temperature resulted in lowering of compressive strain from $-0 \cdot 161$ to -0.009 . Which is due to the difference in co-efficient of thermal expansion between $\mathrm{Ti}$ film $\left(8.5 \times 10^{-6} \mathrm{~K}^{-1}\right)$ and $\mathrm{Si}\left(2.6 \times 10^{-6} \mathrm{~K}^{-1}\right)$ substrate and due to nucleation of silicide phases in Ti interface, therefore, inducing strain in Ti lattice.

Figure 7( $\mathrm{a}$ and $\mathrm{b}$ ) shows 3 -D $\{10 * 1\}$ pole figures of Ti films deposited on Si substrates at 300 and $500^{\circ} \mathrm{C}$, respectively. Both the pole figures, obtained at $2 \theta=40 \cdot 2^{\circ}$ corresponding to $(10 * 1)$ planes, resulted in maximum at the centre, $\psi=0^{\circ}$, suggesting that $(10 * 1)$ planes are nearly parallel to the film surface. Further, it can be noticed that there is difference in the intensity distribution around the rotation angle $(\phi)$ for Ti films deposited at $500^{\circ} \mathrm{C}$. As shown in the tilt angle vs intensity plots, Ti films deposited at $500^{\circ} \mathrm{C}$ reveals increase in the intensity at $\psi \sim 54^{\circ}$ as produced by $(10 * 1)$ poles (figure $7 \mathrm{c}$ ), which is due to the nucleation of titanium-silicide phases.

\section{Conclusions}

In conclusion, structural and morphological properties of $\mathrm{rf}$ magnetron sputtered Ti films deposited on Si (100) substrates were investigated as a function of substrate-bias voltage and substrate temperature. Substrate temperature and substratebias voltage have predominant effect on the film microstructure and orientation of the grains due to their direct dependence on the surface diffusion of adatoms. Deposition rate of Ti films is greatly influenced by ion-bombardment energy, which causes re-sputtering from the film surface. Higher ion energies were found to cause more roughness due to incorporation of surface defects during nucleation and growth of films. Enhanced ion-bombardment causes change in the preferential orientation of Ti grains from $(10 * 0)$ to $(00 * 2)$ and degradation in the crystallinity due to re-sputtering was observed at higher bias voltage. Further, it causes increase in nucleation sites which hinder grain growth and facilitates the formation of nanocrystalline Ti films. Ti films deposited at high substrate temperature leads to the formation of titanium-silicides at the interface and film morphology was found to be changed from 2D-hexagonal plate-like to 3D-spherical shaped $\mathrm{Ti}$ grains as the temperature was increased. As-deposited Ti films tend to relax, when deposited at higher substrate temperature which is governed by lowering of the magnitude of compressive strains developed in films.

\section{Acknowledgements}

One of the authors (BGP) would like to thank Prof S K Ray, Department of Physics, IIT Kharagpur, for supporting X-ray diffraction work carried out in the present work and to IIT Kharagpur, for the financial support for this research. The authors are also grateful to the Central Research Facility, IIT Kharagpur, for various characterization facilities used in this present work.

\section{References}

Aouani $\mathrm{H}$ et al 2009 ACS Nano 32043

Bendavid A, Martin P J, Smith G B, Wielunski L and Kinder T J 1996 Vacuum 471179

Boyer R R 1996 Mater. Sci. Eng. A 213103

Bull S J, Jones A M and McCabe A R 1992 Surf. Coat. Technol. 54 173

Bunshah R F and Juntz R S 1973 Metall. Trans. 421

Chang R C, Chen F Y, Chuang C T and Tung Y C 2010 J. Nanosci. Nanotech. 104562

Chawla V, Jayaganthan R, Chawla A K and Chandra R 2008 Mater. Chem. Phys. 111414

Chawla V, Jayaganthan R, Chawla A K and Chandra R $2009 \mathrm{~J}$. Mater. Process. Technol. 2093444

Dasgupta A, Singh A, Parida P K, Ramaseshan R, Kuppusami P, Saroja S and Vijayalakshmi M 2011 Bull. Mater. Sci. 34483

Fontana L C and Muzart J L R 1998 Surf. Coat. Technol. 10724

Geetha Priyadarshini B, Aich S and Chakraborty M 2011 J. Mater. Sci. $\mathbf{4 6} 2860$

Godfroid T, Gouttebaron R, Dauchot J P, Lecle 're Ph, Lazzaroni R and Hecq 2003 Thin Solid Films $\mathbf{4 3 7} 57$

Guo H and Alam M 1992 Thin Solid Films 212173

Henderson P S, Kelly P J, Arnell R D, Backer H and Bradley J W 2003 Surf. Coat. Technol. 174-175 779

Hoogvliet J C and Bennekom W P V 2001 Electrochim. Acta 47 599

Jeyachandran Y L, Karunagaran B, Narayandass Sa K, Mangalaraj D, Jenkins T E and Martin P J 2006 Mater. Sci. Eng. A 431277

Jeyachandran Y L, Karunagaran B, Narayandass Sa K and Mangalaraj D 2007 Mater. Sci. Eng A 458361

Jin Y, Wu W, Chen L L J, Zhang J, Zuo Y and Fu J 2009 Appl. Surf. Sci. 2554673

Jung M J, Nam K H, Shaginyan L R and Han J G 2003 Thin Solid Films $\mathbf{4 3 5} 145$

Lee S K, Son S H, Kim K S, Park J W, Lim H, Lee J M and Chung E S 2009 Appl. Radiat. 671234

Ljungcrantz H, Hultman L and Sundgren J E 1993 J. Vac. Sci. Technol. A 11543

Makeev M A and Barabasi A L 1997 Appl. Phys. Lett. 712800

Martin N, Baretti D, Rousselot C and Rauch J Y 1998 Surf. Coat. Technol. 107172

Naoe M, Ono S and Hirata T 1991 Mater. Sci. Eng. A 1341292

Ohring M 2006 Materials science of thin films: deposition and structure (Delhi, India: Elsevier)

Oya T and Kusano E 2009 Thin Solid Films 5175837 
Pelleg J, Zevin L Z and Lungo S 1991 Thin Solid Films 197117

Pérez-rigueiro J, Herrero P, Jiménez C, Pérez-casero and Martínezduart J M 1997 Surf. Inter. Anal. 25896

Rickerby D S, Jones A M and Bellamy B A 1989 Surf. Coat. Technol. 37111

Sakta A, Linday J, Srnanek R, Vincze A, Donoval D, Kovac J, Vesely M and Michalka M 2006 Microelectronics J. 371389

Savaloni H, Taherizadeh A and Zendehnam A 2004 Physica B 34944
Song Y H, Cho S J, Jung C K, Bae I S, Boo J H and Kim S 2007 J. Korean Phys. Soc. 511152

Thornton J A 1974 J. Vac. Sci. Technol. 11 666. http://scitation.aip. org/content/avs/journal/jvst/11/4/10.1116/1.1312732

Thornton J A 1986 J. Vac. Sci. Technol. A 43059

Wan W K and Wu S T 1997 Mater. Lett. 30105

Yu R C and Wang W K 1997 Thin Solid Films 302108

Zhang L, Shi L Q, He Z J, Zhang B, Lu Y F, Liu A and Wang Z J 2009 Surf. Coat. Technol. 2033356 